\title{
Paired Emitter-Detector Diode Detection with Dual Wavelength Monitoring for Enhanced Sensitivity to Transition Metals in Ion Chromatography with Post-Column Reaction
}

\author{
Martina O' Toole $^{\mathrm{a}}$, Leon Barron ${ }^{\mathrm{b}}$, Roderick Shepherd ${ }^{\mathrm{c}}$, Brett Paull ${ }^{\mathrm{b}}$, Pavel Nesterenko ${ }^{\mathrm{b}}$ \\ and Dermot Diamond ${ }^{\mathrm{a} *}$ \\ ${ }^{a}$ Adaptive Sensors Group, National Centre for Sensor Research, School of Chemical \\ Sciences, Dublin City University, Dublin 9. \\ ${ }^{\mathrm{b}}$ Separation Science Cluster, National Centre for Sensor Research, School of Chemical \\ Sciences, Dublin City University, Dublin 9. \\ ${ }^{\mathrm{c}}$ Intelligent Polymer Research Institute, University of Wollongong, Wollongong NSW \\ 2522, Australia.
}

\begin{abstract}
The combination of post-column derivatisation and visible detection are regularly employed in ion chromatography (IC) to detect poorly absorbing species. Although this mode is often highly sensitive, one disadvantage is the increase in repeating baseline artifacts associated with out-of-sync pumping systems. The work presented here will demonstrate the use of a second generation design paired emitter-detector diode (PEDDII) detection mode offering enhanced sensitivity to transition metals in IC by markedly reducing this problem by $42 \%$ and also by improving signal-to-noise ratio. First generation designs demonstrated the use of a single integrated PEDD detector cell as a simple, small (15 x $5 \mathrm{~mm}$ ), highly sensitive, low cost photometric detector for the detection of metals in ion chromatography (IC). The basic principle of this detection mode lies in the employment of two linear light emitting diodes (LEDs), one operating in normal mode as a light source and the other in reverse bias serving as a light detector.

The second generation PEDD-II design which consists of an analytical and reference PEDD cell employs two wavelengths whereby one monitors the analyte reaction product
\end{abstract}

\footnotetext{
* Corresponding author: Tel.: +353 1 7005404; Fax: +353 1 7007995; E-mail address: dermot.diamond@dcu.ie
} 
and the second monitors a wavelength close to the isosbestic point. This method obtained improved limits of detection (LOD) of $1 \mu \mathrm{g} \mathrm{L} \mathrm{L}^{-1}$ and $2.5 \mu \mathrm{g} \mathrm{L} \mathrm{L}^{-1}$ respectively for the detection of $\mathrm{Mn}(\mathrm{II})$ - and $\mathrm{Co}(\mathrm{II})-2-($ pyridylazo) resorcinol (PAR) complexes. The optimum LED wavelength to be used for the analytical cell was investigated to maximise peak response. The fabrication process for both the analytical and reference PEDD cells was validated by determining the reproducibility of detectors within a batch. The reproducibility and sensitivity of the PEDD-II detector was then investigated using signals obtained from both intra- and inter-day chromatograms.

Keywords: Light emitting diodes, Optical detector, Miniaturized liquid chromatography detector, Post-column detection, Colorimetric analysis.

\section{Introduction}

A common method employed in liquid chromatography (LC) to improve sensitivity and selectivity is the use of post-column derivatisation. ${ }^{1,2}$ Although widely used in certain liquid chromatography applications, post-column reactions (PCR) do possess some disadvantages such as the increased cost and complexity due to the requirement of an additional pump. An additional disadvantage is the increase in baseline noise. This can be accounted for due to (A) mixing noise arising from imperfect mixing of the eluent and the PCR reagent ${ }^{3}$, (B) cell noise due to the background eluent flowing through the detector, which (in the absence of analyte) produces a finite detector signal and (C) any variations in the mixing profiles of the PCR reagent and eluent will cause baseline noise in the detector. ${ }^{4}$ These factors adversely affect the limit of detection (LOD) as it is typically calculated as three times the standard deviation of the baseline noise. ${ }^{5}$

To improve limit of detection values two approaches can be adopted. The first is to increase the absorbance detected by the analyte of interest, which will result in an increase in the peak height achieved. The second approach is to reduce the baseline noise. The first approach can be achieved by optimising the wavelength at which the analyte is monitored at. UV-vis spectral array detectors are the most commonly employed detection method in laboratory based separation systems, however they are typically not the 
detection of choice in microfluidic separation systems. The small dimensions of microchip separation channels pose a severe problem for sensitive and reliable absorbance measurements. The optical pathlength represented by the channel depth is generally shorter than $30 \mu \mathrm{m} .{ }^{6}$ Light emitting diodes (LEDs) have become increasingly popular as light sources in separation systems ${ }^{7-10}$ due to their advantageous characteristics such as low power consumption, low cost, increasing spectral range coverage (247 nm $1550 \mathrm{~nm}^{11,12}$ ), size, intensity and efficiency. ${ }^{13-15}$ Previously we demonstrated the use of a paired emitter-detector diode (PEDD) system as a highly sensitive photometric detector in liquid chromatography. ${ }^{7}$ The PEDD employs two LEDs, whereby one serves as the light source and the second LED in reverse bias mode is employed as the light detector. Instead of measuring the photocurrent directly, a simple timer circuit is used to measure the time taken for the photocurrent generated by the emitter LED to discharge the detector LED from $5 \mathrm{~V}$ (logic 1 ) to $1.7 \mathrm{~V}$ (logic 0 ) to give digital output directly without using an A/D converter or operation amplifier. This method achieves excellent sensitivity in comparison to (A) a variable wavelength detector typically employed in liquid chromatography $^{7}$ and (B) the more commonly employed method of coupling an LED to a photodiode ${ }^{16}$ When employing an LED as the light source in a photometric detector it is imperative that an LED of narrow bandwidth with an emission $\lambda_{\max }$ close to the analyte absorbance $\lambda_{\max }$ is selected to obtain maximum absorbance.

The reduction of baseline noise can be achieved by employing a number of approaches, for example using pulseless flow for post-column reagent delivery (i.e. a pressurized reagent reservoir).The method undertaken within the work presented here to reduce baseline noise employed a dual wavelength monitoring procedure. This procedure has been successfully employed more commonly in flow injection analysis (FIA) applications. A difference in refractive index (RI) between the sample and the carrier is common, which can lead to an artifact in the absorbance signal often referred to as the Schlieren effect. ${ }^{17}$ An additional problem with detection in FIA occurs when samples have any degree of turbidity. Hooley et al. proposed the use of an LED combined with a beam splitter and two photodiodes for the correction of drift from the light source. ${ }^{18}$ Alternatively, the use of two LEDs first introduced by Worsfold et al. in $1987^{19}$ allows for the correction of colour change, RI or turbidity. ${ }^{17,20-23}$ 
In 2000 Jones applied the method of dual wavelength monitoring to improve sensitivity in ion chromatography employing post-column reactions. ${ }^{24} \mathrm{He}$ achieved a 17 fold improvement in the signal-to-noise ratios calculated for the detection of seven transition metals. This was achieved by monitoring at two wavelengths simultaneously using a spectral array detector. The first wavelength selected was the $\lambda_{\max }$ of the analyte, while the second was selected at a wavelength close to the isosbestic point. Employing simple post run processing to manipulate the data the pump noise was subtracted from the analyte baseline, allowing an improved LOD.

The work presented here will demonstrate improved LOD of transition metals in ion chromatography than previously achieved, ${ }^{7}$ by optimising the wavelength of the emitter LED and by employing the PEDD-II detector to reduce baseline noise introduced by post-column reactions.

\section{Experimental}

\subsection{Chemicals and Reagents}

All chemicals were of reagent grade. The post-column reagent employed for the detection of the transition metal ions consisted of a mixture of $0.4 \mathrm{mM} 4$-(2-pyridylazo) resorcinol monosodium salt hydrate (PAR) (Sigma Aldrich, Dublin, Ireland) and 0.5 M ammonia (35\%, BDH, Poole, England), which was adjusted to $\mathrm{pH}$ 10.5. Manganese chloride tetrahydrate and cobalt nitrate hexahydrate (Sigma Aldrich, Dublin, Ireland) were used

and stock solutions were prepared to a concentration of $1000 \mathrm{mg} \mathrm{L}^{-1}$. Standards were prepared daily from the $1000 \mathrm{mg} \mathrm{L}^{-1}$ stock solutions. The mobile phase, stock solutions and standard solutions were prepared using water from a Millipore Milli-Q water purification system. All samples were vacuum filtered through a $0.45 \mu \mathrm{m}$ filter (Nylaflo®, VWR International, Meath, Ireland) and degassed by sonication. The mobile phase used was $3 \mathrm{mM}$ nitric acid (70\%, East Anglia Chemicals, Suffolk, England). 


\subsection{Equipment}

The system was set up as previously described, ${ }^{7}$ employing a Hewlett Packard series 1050 HPLC system (Agilent Technologies., Dublin) to deliver the eluent at a flow rate of $0.7 \mathrm{~mL} \mathrm{~min}^{-1}$. The chromatograms obtained from the UV-vis spectrophotometric detector were analysed using Agilent Chemstation for LC and LC/MS systems software. Samples were injected using an automated injector with a sample loop of $100 \mu \mathrm{L}$. All separations were carried out on a Nucleosil 100-7 column covalently functionalised with IDA groups of $4 \times 14 \mathrm{~mm}$ in size (particle size $7 \mu \mathrm{m}$ ). A Gilson (MiniPuls 3) peristaltic pump, (Anachem, UK) set at a flow rate setting of $0.38 \mathrm{~mL} \mathrm{~min}^{-1}$ was used for the introduction of the post-column reagent (PCR), which was mixed at room temperature with the eluent using a $0.5 \mathrm{~m}$ PEEK reaction coil $(0.25 \mathrm{~mm}$ i.d., VICI® AG International, Switzerland).

2.3 Fabrication and operation of the PEDD and PEDD-II flow cell detectors

\section{(Single Wavelength) PEDD}

The single wavelength PEDD flow cell was fabricated as previously described ${ }^{25}$ using two $5 \mathrm{~mm}$ LEDs (Farnell in One, Dublin 11, Ireland). As shown in Fig. $1 \mathrm{Mn}$ (II) and Co(II)-PAR complexes had an absorbance $\lambda_{\max }$ of $500 \mathrm{~nm}$ and $510 \mathrm{~nm}$ respectively. Previously an LED with a $\lambda_{\max }$ of $500 \mathrm{~nm}$ was employed to detect $\mathrm{Mn}$ (II) and Co(II)-PAR complexes. In an attempt to improve the absorbance of the $\mathrm{Mn}$ (II) and $\mathrm{Co}$ (II)-PAR complexes two PEDDs were investigated, whereby one employed a green LED with a $\lambda_{\max }$ at $500 \mathrm{~nm}$ and the other a $\lambda_{\max }$ at $510 \mathrm{~nm}$ as the emitter (Fig. 1). Manufacturers' descriptions of LED wavelengths can be nominal as they vary between batches. The 510 nm LEDs (Farnell in One, Dublin 11) obtained for these experiments on investigation actually had a $\lambda_{\max }$ of $507 \mathrm{~nm}$. The detector used was a red LED with a $\lambda_{\max }$ at $660 \mathrm{~nm}$ (Digi-Key, Ireland Part No. 67-1612-ND). The emission spectra of the green emitter LEDs were obtained using an Ocean Optic spectrometer (OOIBase 32 ${ }^{\mathrm{TM}}$, Ocean Optics. Inc., Dunedin, USA). The absorbance spectra of manganese (II) and cobalt (II)-PAR complexes were acquired using a $\mu$ Quant ${ }^{\mathrm{TM}}$ platewell reader (Bio - Tek Instruments, 
Inc., USA). The overlap between absorbing species and the light source provide high sensitivity for the detection of Mn-PAR and Co-PAR. To facilitate comparison, the emission and absorption spectra were normalized to a 0-1 range by dividing values by the maximum emission and absorbance achieved.

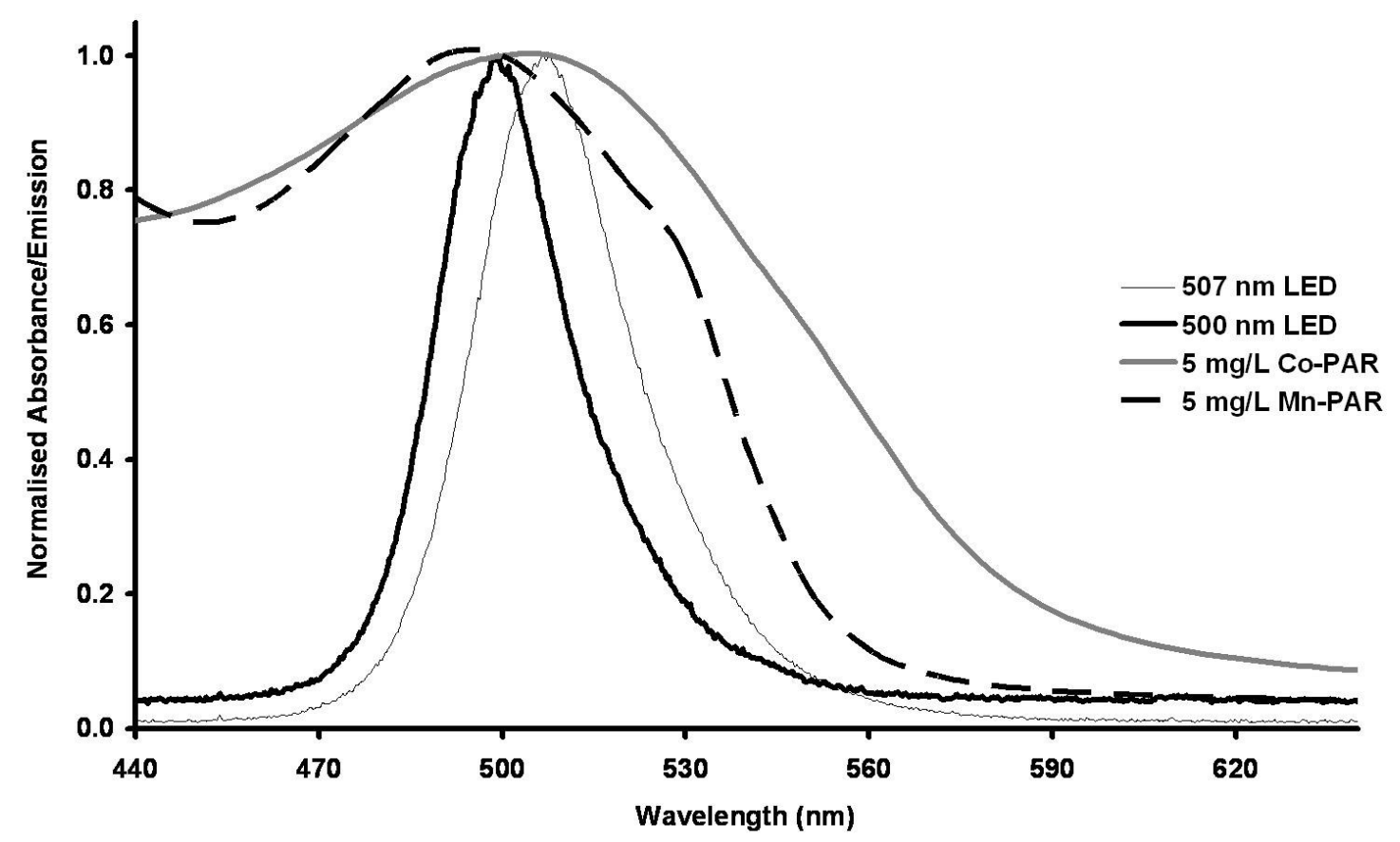

Fig. 1 Emission spectra $\left(\lambda_{\max } 500 \mathrm{~nm}\right.$ (bold line) and $\lambda_{\max } 507 \mathrm{~nm}$ (solid line)) of the emitter LEDs used in the integrated PEDD flow analysis device and the absorption spectra $\left(\lambda_{\max } 500 \mathrm{~nm}\right)$ of $5 \mathrm{mg} \mathrm{L}^{-1} \mathrm{Mn}$-PAR (dashed line) and $\left(\lambda_{\max } 510 \mathrm{~nm}\right) 5 \mathrm{mg} \mathrm{L}^{-1}$ CoPAR (bold grey line).

\section{(Dual Wavelength) PEDD-II}

The dual wavelength PEDD-II consists of two emitter LEDs and two detector LEDs, i.e. one analytical PEDD cell and one reference PEDD. The dual wavelength PEDD-II was fabricated similarly to the single wavelength PEDD. Fig. 2 shows a schematic of the PEDD-II. In most microanalytical systems the light source and the photodetector are normally separate units integrated from the microfluidic manifold, ${ }^{26}$ however the PEDD flow cell (Fig. 2) is a single unit containing light source, fluid channel and detector for flow analysis. ${ }^{7,8,16,25,27}$ The first analytical PEDD employed a green LED with a $\lambda_{\max }$ at 
$507 \mathrm{~nm}$ as the light source and a red LED with a $\lambda_{\max }$ at $660 \mathrm{~nm}$ as the light detector. The second reference PEDD monitored at wavelength near the isosbestic point, which was $450 \mathrm{~nm}$. The LED selected to perform the reference measurement had a $\lambda_{\max }$ at $433 \mathrm{~nm}$ (Roithner Lasertechnik, Austria, Part No. LED450-06U) as it efficiently overlapped with the isosbestic point with a FWHM of ca. $17 \mathrm{~nm}$. The analytical and reference PEDDs were joined by polyether ether ketone (PEEK i.d. $0.75 \mathrm{~mm}$ ) tubing of ca. $1 \mathrm{~cm}$ in length.

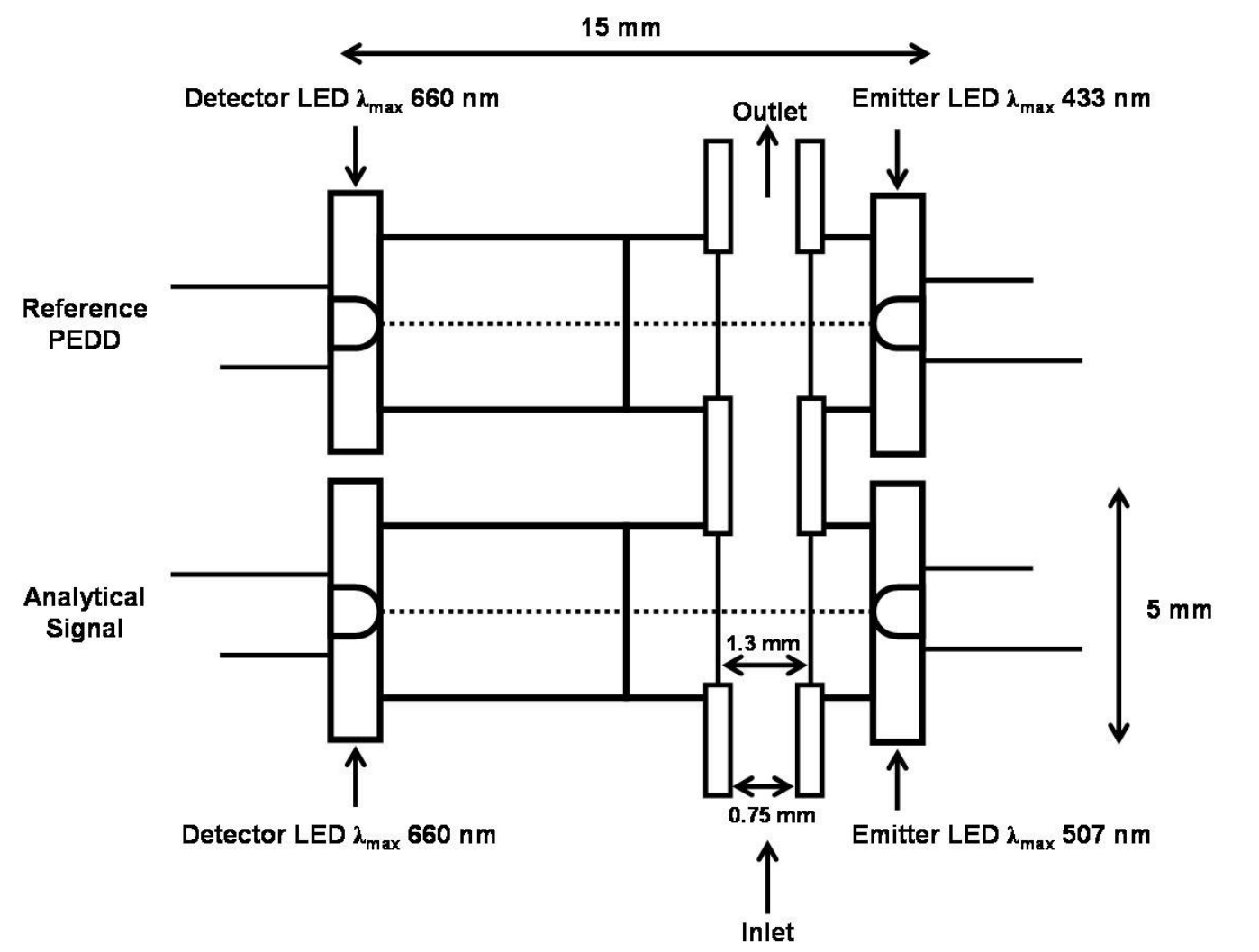

Fig. 2 A schematic of the integrated dual wavelength PEDD-II flow analysis device used for colorimetric detection.

Both the PEDD and PEDD-II flow cells were operated as described in previous work. ${ }^{25} \mathrm{~A}$ $9 \mathrm{~V}$ battery was used as the power source to drive the circuitry from which a voltage regulator was used to control the voltage supply to the LEDs. The light detector LED in input mode was charged up to $5 \mathrm{~V}$ for $100 \mu$ s and then switched to output mode. Photons from the emitter LED generate a photocurrent in the reverse biased detector LED. The detector LED does not measure the photocurrent generated directly but instead the time taken for this photocurrent to discharge the detector LED charge from the initial value of 
$5 \mathrm{~V}$ (logic 1$)$ to a preset value of $1.7 \mathrm{~V}$ (logic 0$)$ is measured with a simple threshold detection and timer circuit. ${ }^{25}{ }^{28}$ This method achieves excellent sensitivity with the added benefit of eliminating the need for an A/D converter or operational amplifier. The data was captured using HyperTerminal software (Microsoft Inc., USA), saved as a text file and then analysed using Excel.

The chromatograms obtained from the variable wavelength spectrophotometric detector were analysed using Agilent Chemstation software.

\section{Results and Discussion}

\subsection{Optimisation of the PEDD monitoring at the analyte wavelength}

The optimum wavelengths to monitor transition metal-PAR complexes have been variously reported in the literature, typically citing the $\lambda_{\max }$ in the range of ca. 495-520 $\mathrm{nm}^{24,29-31}$ Previously the detection of transition metal complexes were obtained using a PEDD with a $\lambda_{\max }$ of $500 \mathrm{~nm} .{ }^{7}$ Under the optimised experimental conditions previously determined the absorbance spectra of $5 \mathrm{mg} \mathrm{L}^{-1} \mathrm{Mn}$ (II) and Co(II)-PAR complexes were acquired using the $\mu$ Quant ${ }^{\mathrm{TM}}$ platewell reader (Bio-Tek Instruments, Inc., USA). A $\lambda_{\max }$ of $500 \mathrm{~nm}$ and $510 \mathrm{~nm}$ were obtained for $5 \mathrm{mg} \mathrm{L}^{-1} \mathrm{Mn}$ (II) and Co(II)-PAR complexes respectively (Fig. 1). To determine if improved analyte response with respect to that previously reported could be obtained a PEDD with a reported $\lambda_{\max }$ of $507 \mathrm{~nm}$ was investigated. A $0.25 \mathrm{mg} \mathrm{L}^{-1}$ mixture of $\mathrm{Mn}$ (II) and Co(II) was prepared and injected $(n=$ 10). The mean peak height (change in discharge time, $\mu \mathrm{s}$ ) calculated for $\mathrm{Mn}(\mathrm{II})$ and Co(II)-PAR complexes from both PEDDs $\left(\lambda_{\max } 500 \mathrm{~nm}\right.$ and $\left.507 \mathrm{~nm}\right)$ are shown in Table 1. 
Table 1 Comparison peak height (change in discharge time, $\mu \mathrm{s}$ ) data acquired from PEDDs with a $\lambda_{\max }$ of $500 \mathrm{~nm}$ and $507 \mathrm{~nm}$ for the detection of $0.25 \mathrm{mg} \mathrm{L}^{-1} \mathrm{Mn}$ (II) and Co(II)-PAR complexes $(n=10)$.

\begin{tabular}{|l|c|c|c|c|}
\hline & \multicolumn{2}{|c|}{ 507 nm Peak Height $(\boldsymbol{\mu s})$} & \multicolumn{2}{c|}{ 500 nm Peak Height $(\boldsymbol{\mu s})$} \\
\hline 0.25 mg L $^{-1}$ & Mn-PAR & Co-PAR & Mn-PAR & Co-PAR \\
\hline Average $(n=\mathbf{1 0})$ & 898 & 375 & 405 & 114 \\
\hline Std Dev $(n=\mathbf{1 0})$ & 31 & 14 & 5 & 3 \\
\hline RSD\% & 4 & 4 & 1 & 3 \\
\hline
\end{tabular}

As shown in Table 1 the average peak height obtained employing the $\left(\lambda_{\max } 507 \mathrm{~nm}\right)$ PEDD for $0.25 \mathrm{mg} \mathrm{L}^{-1} \mathrm{Mn}$ (II) and Co(II)-PAR complexes were respectively 2.2 and 3.3 times greater than that measured with the $\left(\lambda_{\max } 500 \mathrm{~nm}\right)$ PEDD. To prove experimentally that the PEDD with a $\lambda_{\max }$ of $507 \mathrm{~nm}$ was the optimum wavelength for the detection of $\mathrm{Mn}$ (II) and Co(II)-PAR complexes due to the efficient overlap of the emission and absorption spectra and not due merely to an improvement in the fabrication of the PEDD, 4 PEDDs of each wavelength were prepared. A mixture of $0.25 \mathrm{mg} \mathrm{L}^{-1} \mathrm{Mn}$ and Co was injected onto the column $(n=10)$ and were monitored with (A) 4 individual $\left(\lambda_{\max } 500\right.$ nm) PEDDs, (B) 4 individual $\left(\lambda_{\max } 507 \mathrm{~nm}\right.$ ) PEDDs and (C) a variable wavelength detector (VWD) $(500 \mathrm{~nm})$. The $0.25 \mathrm{mg} \mathrm{L}^{-1} \mathrm{Mn}$ and Co mixture was injected ten times for each PEDD. The results shown in Table 2 were obtained by calculating the average peak heights (change in discharge time, $\mu \mathrm{s})$ from the ten injections for each $\left(\lambda_{\max } 500 \mathrm{~nm}\right)$ PEDD. An overall average for the $4\left(\lambda_{\max } 500 \mathrm{~nm}\right)$ PEDDs was then calculated. This was repeated for the $4\left(\lambda_{\max } 507 \mathrm{~nm}\right)$ PEDDs investigated. The average peak heights (change in discharge time, $\mu \mathrm{s}$ ) measured using the ( $\lambda_{\max } 507 \mathrm{~nm}$ ) PEDDs (Fig. 3) for $0.25 \mathrm{mg} \mathrm{L}^{-1}$ $\mathrm{Mn}(\mathrm{II})$ and $\mathrm{Co}(\mathrm{II})-\mathrm{PAR}$ complexes are approximately 2 times that of the average peak heights measured using the $\left(\lambda_{\max } 500 \mathrm{~nm}\right)$ PEDDs. 


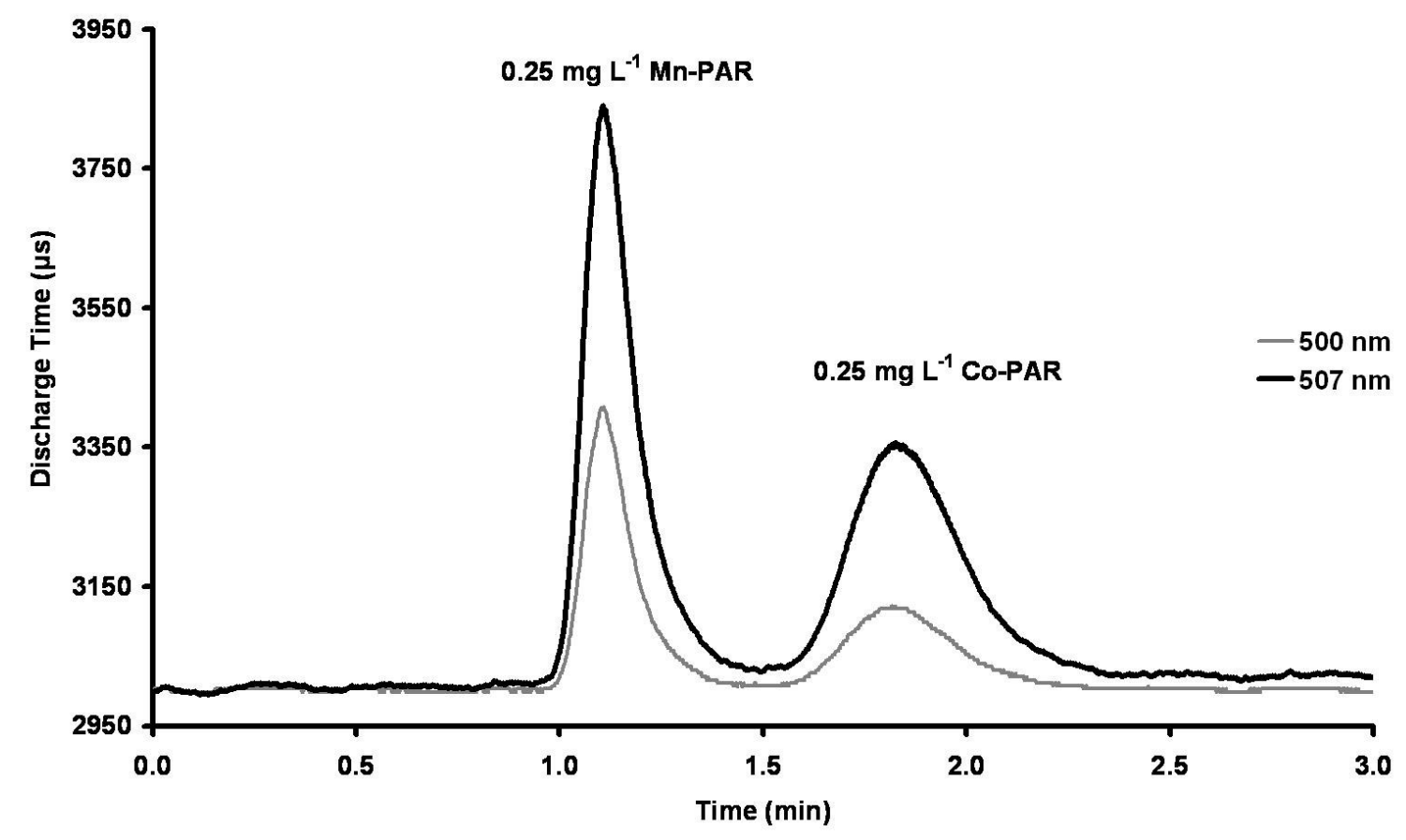

Fig. 3 Comparison of average traces for the detection of $0.25 \mathrm{mg} \mathrm{L}^{-1} \mathrm{Mn}-\mathrm{PAR}$ and CoPAR using (A) $4 \times$ ( $\lambda_{\max } 507 \mathrm{~nm}$ ) PEDDs (bold line) and (B) $4 \times\left(\lambda_{\max } 500 \mathrm{~nm}\right)$ PEDDs (grey line). Each trace is an average of 10 injections.

The average peak heights measured for $0.25 \mathrm{mg} \mathrm{L}^{-1} \mathrm{Mn}(\mathrm{II})$ and Co(II)-PAR complexes using the VWD $\left(\lambda_{\max } 500 \mathrm{~nm}\right)$ as outlined in Table 2 had a RSD\% of 3.7 and $6.1 \%$ respectively. The reproducibility of the peak heights achieved for the metal complexes using the 4 individual $\left(\lambda_{\max } 500 \mathrm{~nm}\right)$ PEDDs and the 4 individual $\left(\lambda_{\max } 507 \mathrm{~nm}\right)$ PEDDs calculated a highest RSD of $4.8 \%$. 
Table 2 Determination of the reproducibility of detectors (A) $\left(\lambda_{\max } 500 \mathrm{~nm}\right)$ PEDD, (B) $\left(\lambda_{\max } 507 \mathrm{~nm}\right)$ PEDD and (C) VWD $(500 \mathrm{~nm})(n=4)$.

\begin{tabular}{|c|c|c|c|}
\hline $0.25 \mathrm{mg} \mathrm{L}^{-1}$ & Peak Height $(n=4)$ & Standard Deviation & $R S D \%$ \\
\hline \multicolumn{4}{|c|}{ PEDD $\left(\lambda_{\max } 500 \mathrm{~nm}\right)$} \\
\hline Mn-PAR & $441 \mu \mathrm{s}$ & $21 \mu \mathrm{s}$ & $5 \mu \mathrm{s}$ \\
\hline Co-PAR & $152 \mu \mathrm{s}$ & $4 \mu \mathrm{s}$ & $3 \mu \mathrm{s}$ \\
\hline \multicolumn{4}{|c|}{ PEDD $\left(\lambda_{\max } 507 \mathrm{~nm}\right)$} \\
\hline Mn-PAR & $827 \mu \mathrm{s}$ & $23 \mu \mathrm{s}$ & $3 \mu \mathrm{s}$ \\
\hline Co-PAR & $351 \mu \mathrm{s}$ & $12 \mu \mathrm{s}$ & $3 \mu \mathrm{s}$ \\
\hline \multicolumn{4}{|c|}{$V W D\left(\lambda_{\max } 500 \mathrm{~nm}\right)$} \\
\hline Mn-PAR & 1291 & 48 & 4 \\
\hline Co-PAR & 451 & 28 & 6 \\
\hline
\end{tabular}

The same VWD at the same wavelength was employed throughout the experiments. The results shown in Table 2 demonstrate that the PEDD can be fabricated reproducibly, providing a reliable response over a long period of time ( 3 months). This is of utmost importance if the PEDD is a viable detector in field deployable systems and sensor networks.

\subsection{Intra/Inter-day reproducibility of the PEDD flow cell}

Reproducibility is an important characteristic for a field deployable device. To demonstrate the intra and inter-day reproducibility within an individual PEDD flow cell a mixture of $0.25 \mathrm{mg} \mathrm{L}^{-1} \mathrm{Mn}$ (II) and Co (II) was injected on the column. The separation was monitored using a PEDD $\left(\lambda_{\max } 507 \mathrm{~nm}\right)$ and a VWD $(500 \mathrm{~nm})$ for comparison. The same PEDD was used for all experiments to determine the reproducibility within an individual PEDD.

\section{Intra-Day Reproducibility}


As shown in Table 3 the chromatograms achieved from the VWD demonstrate good reproducibility with relative standard deviations of $1.5 \%$ and $2.0 \%, n=10$ for $0.25 \mathrm{mg} \mathrm{L}^{-}$

${ }^{1} \mathrm{Mn}$ (II) and Co(II)-PAR complexes respectively. The peak height (change in discharge time, $\mu \mathrm{s}$ ) data obtained from the PEDD was plotted against retention time (minutes). As shown in Table 3 the PEDD matches the reproducibility of the VWD. The PEDD demonstrated relative standard deviations of $1.6 \%$ and $0.9 \%, n=10$ for $0.25 \mathrm{mg} \mathrm{L}^{-1}$ $\mathrm{Mn}$ (II) and Co(II)-PAR complexes respectively. The signal-to-noise ratios calculated using the $\left(\lambda_{\max } 507 \mathrm{~nm}\right)$ PEDD for the detection of $0.25 \mathrm{mg} \mathrm{L}^{-1} \mathrm{Mn}$-PAR and Co-PAR complexes were ca. 1.8 and 2.3 times higher than those calculated using the VWD.

\section{Inter-Day Reproducibility}

To investigate the inter-day reproducibility of a PEDD flow cell, a single $\left(\lambda_{\max } 507 \mathrm{~nm}\right)$ PEDD was selected and a $100 \mu \mathrm{L}$ injection of $0.25 \mathrm{mg} \mathrm{L}^{-1} \mathrm{Mn}$ (II) and Co(II) was made onto the column $(n=10)$. This was repeated for three consecutive days employing the same PEDD and experimental conditions. The data obtained from the $\left(\lambda_{\max } 507 \mathrm{~nm}\right)$ PEDD and the VWD are given in Table 3. The VWD achieved peak height relative standard deviations of $1.0 \%$ and $2.1 \%$ for $0.25 \mathrm{mg} \mathrm{L}^{-1} \mathrm{Mn}$ (II) and Co(II)-PAR complexes $(n=3)$ respectively. 
Table 3 Comparison data for the determination of the intra and inter-day reproducibility within an individual $\left(\lambda_{\max } 507 \mathrm{~nm}\right)$ PEDD and a VWD $(500 \mathrm{~nm})(n=10)$.

\begin{tabular}{|c|c|c|c|c|}
\hline$n=\mathbf{1 0}$ & \multicolumn{2}{|c|}{$\operatorname{PEDD}\left(\lambda_{\max } 500 \mathrm{~nm}\right)$} & \multicolumn{2}{|c|}{ VWD $(500 \mathrm{~nm})$} \\
\hline $0.25 \mathrm{mg} \mathrm{L}^{-1}$ & Mn-PAR & Co-PAR & Mn-PAR & Co-PAR \\
\hline \multicolumn{5}{|c|}{ Inter-Day Reproducibility } \\
\hline Peak Height $(\mu s)$ & $786 \pm 13$ & $337 \pm 3$ & $1303 \pm 20$ & $441 \pm 9$ \\
\hline RSD\% & 2 & 1 & 2 & 2 \\
\hline Baseline Noise (o) $\mu \mathrm{s}$ & 2 & 2 & 6 & 6 \\
\hline $\mathbf{S} / \mathbf{N}$ & 401 & 172 & 217 & 73 \\
\hline \multicolumn{5}{|c|}{ Intra-Day Reproducibility } \\
\hline Peak Height ( $\mu s)$ & $868 \pm 13$ & $378 \pm 11$ & $1256 \pm 46$ & $425 \pm 9$ \\
\hline RSD\% & 2 & 3 & 4 & 2 \\
\hline Baseline Noise (o) $\mu \mathrm{s}$ & 2 & 2 & 6 & 6 \\
\hline $\mathbf{S} / \mathbf{N}$ & 434 & 189 & 209 & 71 \\
\hline
\end{tabular}

The peak height (change in discharge time, $\mu \mathrm{s})$ measured using the $\left(\lambda_{\max } 507 \mathrm{~nm}\right)$ PEDD demonstrated relative standard deviations of $1.5 \%$ and $2.8 \%$ for $0.25 \mathrm{mg} \mathrm{L}^{-1} \mathrm{Mn}$ (II) and Co(II)-PAR complexes $(n=3)$ respectively. The PEDD flow cell achieved intra/inter-day reproducibility comparable to values obtained from a variable wavelength detector highlighting it's suitability as a potential detector in a miniaturised field deployable chromatography system.

\subsection{PEDD-II (dual wavelength monitoring)}

\section{Selection of Reference LED}

As mentioned previously post-column reaction systems can add substantially to the baseline noise in liquid chromatography. A dual wavelength monitoring procedure was investigated to improve limits of detection in ion chromatography employing postcolumn reactions by reducing the background noise. The procedure entailed monitoring at two wavelengths simultaneously. The $\left(\lambda_{\max } 507 \mathrm{~nm}\right)$ PEDD was selected to monitor at 
$\lambda_{\max }$ of the analyte, while the second was selected at a wavelength close to the isosbestic point. The isosbestic point was determined by obtaining the absorbance spectra of increasing concentrations of both $\mathrm{Mn}$ (II) and $\mathrm{Co}(\mathrm{II})-\mathrm{PAR}$ complexes. The ideal isosbestic point to monitor at was determined as $450 \mathrm{~nm}$, however commercially available LEDs citing a $\lambda_{\max }$ in this region typically have an emission spectrum possessing a FWHM of approximately $80 \mathrm{~nm}$. Alternatively an LED with a $\lambda_{\max }$ of $433 \mathrm{~nm}$ (FWHM $17 \mathrm{~nm}$ ) was investigated as the wavelength to monitor the baseline noise. Various concentrations of $\mathrm{Mn}(\mathrm{II})$ and $\mathrm{Co}(\mathrm{II})$ were injection on the column and monitored using the dual wavelength PEDD-II (Analyte Signal: $\lambda_{\max } 507 \mathrm{~nm}$ and Reference Signal: $\lambda_{\max } 433 \mathrm{~nm}$ ).

\section{PEDD-II (Analyte Signal: $\lambda_{\max } 507 \mathrm{~nm}$ and Reference Signal: $\lambda_{\max } 433 \mathrm{~nm}$ )}

The PEDD-II consisting of the two PEDDS was driven from the same circuit board with a data output rate of 16 data points per second. The data manipulation was carried out post run. On acquiring the data from the $\left(\lambda_{\max } 433 \mathrm{~nm}\right)$ PEDD which monitored the baseline only, the amplitude of the baseline noise was normalised and subtracted from the $\left(\lambda_{\max } 507 \mathrm{~nm}\right)$ PEDD Mn(II) and Co(II)-PAR data set. The experiment was repeated three times. 

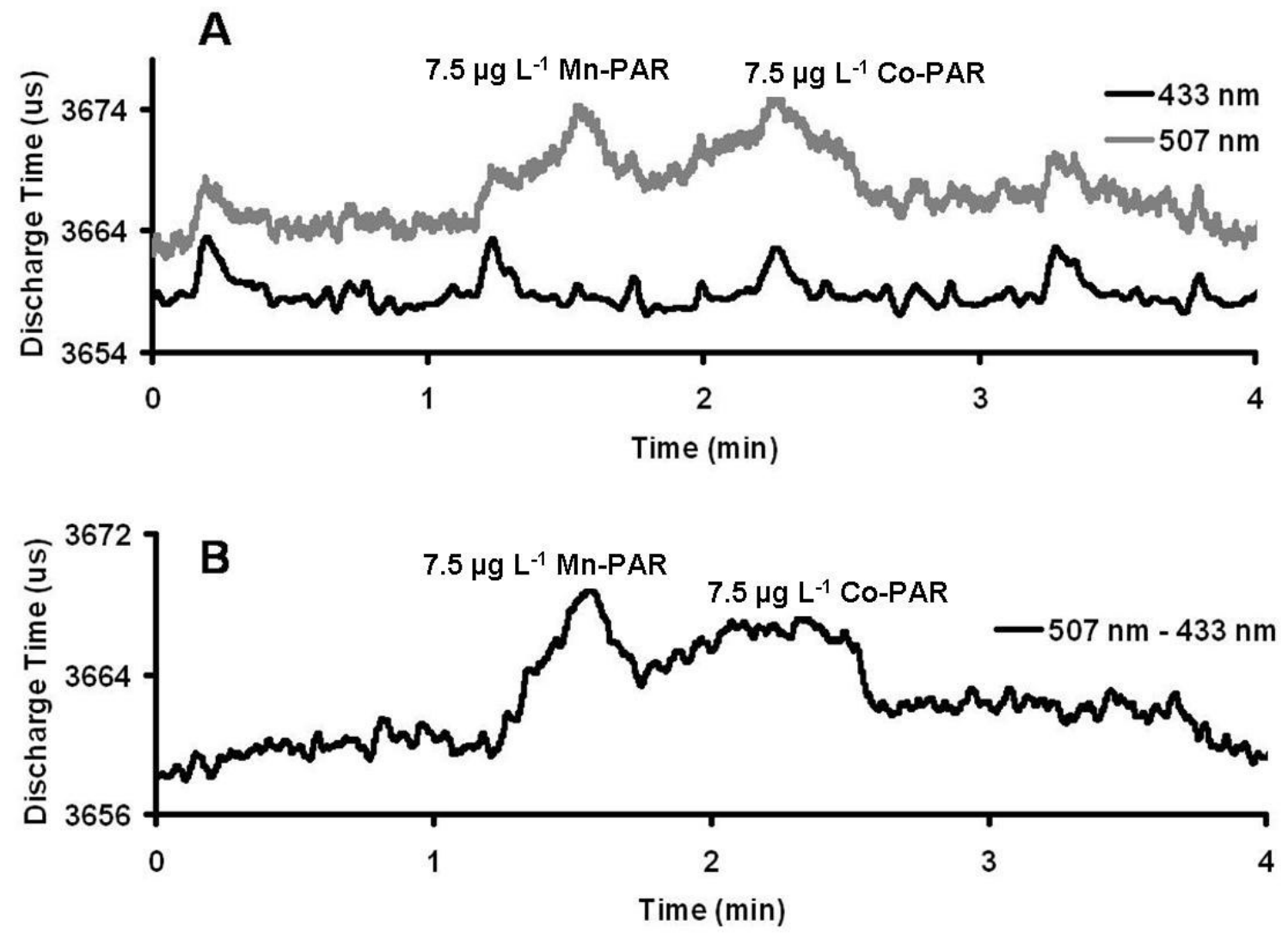

Fig. 4 Comparison data acquired from (A) the PEDD-II (analyte PEDD ( $\lambda_{\max } 507 \mathrm{~nm}$, bold line) and reference PEDD ( $\lambda_{\max } 433 \mathrm{~nm}$, solid line)) and (B) post data analysis for the detection of $7.5 \mu \mathrm{g} \mathrm{L}^{-1} \mathrm{Mn}$ (II) and $\mathrm{Co}(\mathrm{II})-\mathrm{PAR}$ complexes.

As shown in Fig. 4A for the detection of $7.5 \mu \mathrm{g} \mathrm{L} \mathrm{L}^{-1} \mathrm{Mn}(\mathrm{II})$ and Co(II)-PAR complexes the reference PEDD ( $\lambda_{\max } 433 \mathrm{~nm}$ ) monitors the baseline noise only and does not detect the transition metal-PAR complexes. Fig. 4B shows the average $(n=3)$ plot measured (post data analysis) for the detection of $7.5 \mu \mathrm{g} \mathrm{L}^{-1} \mathrm{Mn}$ (II) and Co(II)-PAR complexes using the dual wavelength PEDD-II $\left(\lambda_{\max } 507 \mathrm{~nm}-\lambda_{\max } 433 \mathrm{~nm}\right.$ ). The average peak height (change in discharge time, $\mu \mathrm{s}$ ) calculated for both the $\mathrm{Mn}(\mathrm{II})$ and $\mathrm{Co}(\mathrm{II})-\mathrm{PAR}$ complexes were $9.8 \mu \mathrm{s} \pm 0.2 \mu \mathrm{s}$ and $6.1 \mu \mathrm{s} \pm 1.0 \mu \mathrm{s}$. The average standard deviation $(3 \sigma)$ of the baseline calculated was $2.6 \mu \mathrm{s}(n=3)$. A signal-to-noise ratio of 11.5 and 7.2 were achieved for $\mathrm{Mn}(\mathrm{II})$ and $\mathrm{Co}(\mathrm{II})-\mathrm{PAR}$ complexes respectively. This showed an increase of $55 \%$ in the signal-to-noise ratio calculated for the detection of Mn-PAR and a $72 \%$ 
increase for the detection of Co-PAR in comparison to the data calculating using the single PEDD $\left(\lambda_{\max } 507 \mathrm{~nm}\right)$ as outlined in Table 4.

Table 4 Comparative data for the detection of $7.5 \mu \mathrm{g} \mathrm{L}^{-1} \mathrm{Mn}$ (II) and Co(II)-PAR complexes with (A) a single PEDD ( $\left.\lambda_{\max } 507 \mathrm{~nm}\right)$, (B) dual PEDD ( $\lambda_{\max } 507 \mathrm{~nm}-433$ $\mathrm{nm})$ and $(\mathrm{C})$ a VWD $(500 \mathrm{~nm})(n=3)$.

\begin{tabular}{|c|c|c|c|c|c|c|}
\hline & \multicolumn{3}{|c|}{$7.5 \mu \mathrm{g} \mathrm{L}^{-1} \mathrm{Mn}-\mathrm{PAR}$} & \multicolumn{3}{|c|}{$7.5 \mu \mathrm{g} \mathrm{L}^{-1} \mathrm{Co}-\mathrm{PAR}$} \\
\hline & PEDD & PEDDII & VWD & PEDD & PEDDII & VWD \\
\hline Peak Height ( $\mu \mathrm{s})$ & $9.9 \pm 0.6$ & $9.8 \pm 0.2$ & $6.8 \pm 0.5$ & $5.5 \pm 0.5$ & $6.1 \pm 1.0$ & - \\
\hline  & 4.2 & 2.6 & 6.2 & 4.2 & 2.6 & - \\
\hline $\mathbf{S} / \mathbf{N}$ & 7.4 & 11.5 & 3.3 & 4.1 & 7.2 & - \\
\hline
\end{tabular}

Employing the dual wavelength monitoring procedure obtained an overall $42 \%$ reduction in the standard deviation of the baseline. As shown in Table 4 the VWD could not detect

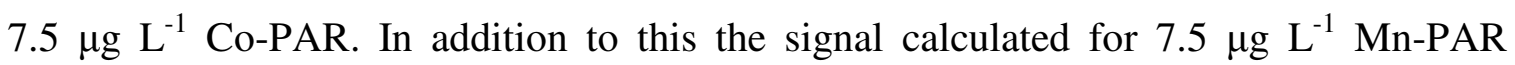
employing the VWD could reliably be detected. The peak height was calculated as $6.8 \pm$ 0.5 however the average baseline standard deviation $(3 \sigma)$ was determined to be $6.2 \pm 0.2$. The signal-to-noise ratio calculated using the PEDD-II for the detection of $7.5 \mu \mathrm{g} \mathrm{L}^{-1} \mathrm{Mn}$ PAR in comparison to the VWD demonstrated approximately a $250 \%$ increase. 




Fig. 5 Replicate injections of transition metals $\mathrm{Mn}(\mathrm{II})$ and $\mathrm{Co}$ (II) detected employing the PEDD-II $\left(\lambda_{\max } 507 \mathrm{~nm}-433 \mathrm{~nm}\right)$ at $(\mathrm{A})$ varying concentrations $\left(25-1000 \mu \mathrm{g} \mathrm{L}^{-1}\right)$ and (B) LODs of $1 \mu \mathrm{g} \mathrm{L}^{-1}$ and $2.5 \mu \mathrm{g} \mathrm{L}^{-1}$ for Mn(II)- and Co(II)-PAR complexes respectively.

The limits of detection (LOD) calculated for the detection of $\mathrm{Mn}$ (II) and $\mathrm{Co}$ (II)-PAR complexes using the $\left(\lambda_{\max } 500 \mathrm{~nm}\right)$ PEDD, $\left(\lambda_{\max } 507 \mathrm{~nm}\right)$ PEDD and the dual PEDD $\left(\lambda_{\max } 507 \mathrm{~nm}-\lambda_{\max } 433 \mathrm{~nm}\right)$ are summarised in Table 5. The LODs obtained employing the dual wavelength PEDD-II as shown in Fig. 5 were ca. 5 and 2 times lower than the LODs calculated for both $\mathrm{Mn}$ (II) and Co(II)-PAR complexes using the single wavelength $\left(\lambda_{\max } 500 \mathrm{~nm}\right)$ PEDD previously reported ${ }^{7}$ and

Table 5 Comparative data of the limits of detection acquired using the (A) $\left(\lambda_{\max } 500 \mathrm{~nm}\right)$ PEDD, (B) $\left(\lambda_{\max } 507 \mathrm{~nm}\right)$ PEDD and (C) a dual wavelength PEDD-II ( $\lambda_{\max } 507 \mathrm{~nm}-\lambda_{\max }$ $433 \mathrm{~nm}$ ) 


\begin{tabular}{|l|c|c|c|}
\hline Analyte & PEDD $\left(\boldsymbol{\lambda}_{\max } \mathbf{5 0 0} \mathbf{~ n m}\right)$ & PEDD $\left(\boldsymbol{\lambda}_{\max } \mathbf{5 0 7} \mathbf{~ n m}\right)$ & PEDD-II \\
\hline Mn-PAR & $4.9 \mu \mathrm{g} \mathrm{L}^{-1}$ & $2.5 \mu \mathrm{g} \mathrm{L}^{-1}$ & $1.0 \mu \mathrm{g} \mathrm{L}^{-1}$ \\
\hline Co-PAR & $5.3 \mu \mathrm{g} \mathrm{L}^{-1}$ & $5.0 \mu \mathrm{g} \mathrm{L}^{-1}$ & $2.5 \mu \mathrm{g} \mathrm{L}^{-1}$ \\
\hline
\end{tabular}

\section{Conclusions}

The results obtained using the integrated single and dual wavelength PEDD-II flow cell have demonstrated improved sensitivity, selectivity and signal-to-noise ratios than previously reported for the detection of transition metals $\mathrm{Mn}$ (II) and $\mathrm{Co}$ (II) coupled with the post-column reagent PAR. This was achieved through two approaches. Firstly by optimising the wavelength in which to monitor the transition metal-PAR complexes and secondly by employing the PEDD-II which employs a dual wavelength monitoring procedure. Intra and inter-day reproducibility within an individual single wavelength $\left(\lambda_{\max } 507 \mathrm{~nm}\right)$ PEDD were comparable to the relative standard deviations calculated using the VWD for the detection of $0.25 \mathrm{mg} \mathrm{L}^{-1} \mathrm{Mn}$ (II) and Co(II)-PAR complexes.

Often when attempting to miniaturise components of analytical instruments, such as the detector there is a loss in sensitivity. The single wavelength $\left(\lambda_{\max } 507 \mathrm{~nm}\right)$ PEDD flow cell however can detect lower concentration levels of $\mathrm{Mn}$ (II) and Co(II)-PAR complexes than that of an expensive, commercially available bench top instrument. The employment of a dual wavelength monitoring PEDD-II $\left(\lambda_{\max } 507 \mathrm{~nm}-\lambda_{\max } 433 \mathrm{~nm}\right)$ for the detection of transition metal-PAR complexes enhanced sensitivity further obtaining LODs of 1.0 $\mu \mathrm{g} \mathrm{L}{ }^{-1}$ and $2.5 \mu \mathrm{g} \mathrm{L}^{-1}$ for the detection of $\mathrm{Mn}$ (II) and Co(II)-PAR complexes respectively. Employing the dual wavelength monitoring procedure obtained an overall $42 \%$ reduction in the standard deviation of the baseline. The results presented within in this work, show huge potential for the use of a dual wavelength PEDD-II for the purpose of improving limit of detection by reducing baseline noise in post-column reaction systems.

This optical detector has the potential for very broad analytical applications, given that it offers high sensitivity and precision with excellent signal-to-noise characteristics. The PEDD flow cell offers significant advantages as a potential absorbance detector in a miniaturised field deployable low pressure ion chromatography system. The optical 
detector cannot replace a standard UV-vis spectrophotometer, however it offers many advantages such as its low cost, versatility, simplicity, ease of use, low power consuming, small in size and can be easily integrated into a field deployable liquid chromatography system.

\section{Acknowledgements}

The Authors wish to thank Science Foundation Ireland SFI for grant support under the Adaptive Information Cluster Award (SFI 03/IN3/1361).

\section{References}

1. U. A. T. Brinkman, Chromatographia, 1987, 24, 190-200.

2. P. K. Dasgupta, J. Chromatogr. Sci., 1989, 27, 422-448.

3. R. M. Cassidy, S. Elchuk and P. K. Dasgupta, Anal. Chem. (Washington, DC, U. S.), 1987, 59, 85-90.

4. P. R. Haddad and P. E. Jackson, Ion Chromatography - Principles and Applications, Elsevier, 1990.

5. H. Small, Ion Chromatography, Plenum Press, New York and London, 1989.

6. $\quad$ S. Götz and U. Karst, Anal. Bioanal. Chem., 2007, 387, 183-192.

7. M. O'Toole, K. T. Lau, B. Schazmann, R. Shepherd, P. N. Nesterenko, B. Paull and D. Diamond, Analyst, 2006, 131, 938-943.

8. L. Barron, P. N. Nesterenko, D. Diamond, M. O’Toole, K. T. Lau and B. Paull, Anal. Chim. Acta, 2006, 577, 32-37.

9. M. King, B. Paull, P. R. Haddad and M. Macka, Analyst, 2002, 127, 1564-1567.

10. Q. Lu and G. E. Collins, Analyst, 2001, 126, 429-432.

11. http://www.roithner-laser.com/

12. http://www.s-et.com/

13. P. K. Dasgupta, I. Y. Eom, K. J. Morris and J. Li, Anal. Chim. Acta, 2003, 500, 337-364.

14. P. K. Dasgupta, H. S. Bellamy, H. Liu, J. L. Lopez, E. L. Loree, K. Morris, K. Petersen and K. A. Mir, Talanta, 1993, 40, 53-74.

15. M. O'Toole and D. Diamond, Sensors, 2008, 8, 2453-2479. 
16. M. O'Toole, K. T. Lau, R. Shepherd, C. Slater and D. Diamond, Anal. Chim. Acta, 2007, 597, 290-294.

17. H. Liu and P. K. Dasgupta, Anal. Chim. Acta, 1994, 289, 347-353.

18. D. J. Hooley and R. E. Dessy, Anal. Chem., 1983, 55, 313-320.

19. P. J. Worsfold, J. R. Clinch and H. Casey, Anal. Chim. Acta, 1987, 197, 43-50.

20. J. Huang, H. Liu, A. Tan, J. Xu and X. Zhao, Talanta, 1992, 39, 589-592.

21. E. A. G. Zagatto, M. A. Z. Arruda, A. O. Jacintho and I. L. Mattos, Anal. Chim. Acta, 1990, 234, 153-160.

22. A. Suzuki, J. Kondoh, Y. Matsui, S. Shiokawa and K. Suzuki, Sens. Actuators, B, 2005, 106, 383-387.

23. I.-Y. Eom and P. K. Dasgupta, Talanta, 2006, 69, 906-913.

24. P. Jones, Analyst, 2000, 125, 803-806.

25. M. O'Toole, K. T. Lau and D. Diamond, Talanta, 2005, 66, 1340-1344.

26. O. Geschke, H. Klank and P. Tellemann, Microsystem Engineering of Lab-on-achip Devices, WILEY-VCH, 2004.

27. M. O'Toole, R. Shepherd, K. T. Lau and D. Diamond, SPIE Optics East 2007, Boston, MA, USA, 2007.

28. K. T. Lau, S. Baldwin, R. L. Shepherd, P. H. Dietz, W. S. Yerazunis and D. Diamond, Talanta, 2004, 63, 167-173.

29. P. Nesterenko and P. Jones, J. Chromatogr. A, 1997, 770, 129-135.

30. E. Sugrue, P. Nesterenko and B. Paull, J. Sep. Sci., 2004, 27, 921-930.

31. E. Sugrue, P. Nesterenko and B. Paull, Anal. Chim. Acta, 2005, 553, 27-35. 